\title{
Frequencies of circulating MDSC correlate with clinical outcome of melanoma patients treated with ipilimumab
}

\author{
Christiane Meyer · Laurène Cagnon · Carla M. Costa-Nunes · Petra Baumgaertner • \\ Nicole Montandon · Loredana Leyvraz • Olivier Michielin · Emanuela Romano • \\ Daniel E. Speiser
}

Received: 25 September 2013 / Accepted: 5 December 2013 / Published online: 20 December 2013

(C) Springer-Verlag Berlin Heidelberg 2013

\begin{abstract}
Metastatic melanoma has a poor prognosis with high resistance to chemotherapy and radiation. Recently, the anti-CTLA-4 antibody ipilimumab has demonstrated clinical efficacy, being the first agent to significantly prolong the overall survival of inoperable stage III/IV melanoma patients. A major aim of patient immune monitoring is the identification of biomarkers that predict clinical outcome. We studied circulating myeloid-derived suppressor cells (MDSC) in ipilimumab-treated patients to detect alterations in the myeloid cell compartment and possible correlations with clinical outcome. $\mathrm{Lin}^{-} \mathrm{CD} 14^{+}$ $\mathrm{HLA}^{-} \mathrm{DR}^{-}$monocytic MDSC were enriched in peripheral blood of melanoma patients compared to healthy donors (HD). Tumor resection did not significantly alter MDSC frequencies. During ipilimumab treatment, MDSC frequencies did not change significantly compared to baseline levels. We observed high inter-patient differences. MDSC frequencies in ipilimumab-treated patients were independent of baseline serum lactate dehydrogenase levels but tended to increase in patients with severe metastatic disease (M1c) compared to patients with metastases in skin or lymph nodes only (M1a), who had frequencies comparable
\end{abstract}

Electronic supplementary material The online version of this article (doi:10.1007/s00262-013-1508-5) contains supplementary material, which is available to authorized users.

C. Meyer · L. Cagnon - C. M. Costa-Nunes · P. Baumgaertner · N. Montandon · L. Leyvraz · O. Michielin - D. E. Speiser Ludwig Center for Cancer Research of the University

of Lausanne, Lausanne, Switzerland

O. Michielin · E. Romano $\cdot$ D. E. Speiser $(\bowtie)$

Service of Medical Oncology, Department of Oncology,

Lausanne University Hospital Center (CHUV), Lausanne,

Switzerland

e-mail: doc@dspeiser.ch to HD. Interestingly, clinical responders to ipilimumab therapy showed significantly less $\operatorname{lin}^{-} \mathrm{CD} 14^{+} \mathrm{HLA}^{-} \mathrm{DR}^{-}$ cells as compared to non-responders. The data suggest that the frequency of monocytic MDSC may be used as predictive marker of response, as low frequencies identify patients more likely benefitting from ipilimumab treatment. Prospective clinical trials assessing MDSC frequencies as potential biomarkers are warranted to validate these observations.

Keywords MDSC $\cdot$ Ipilimumab $\cdot$ CTLA-4 $\cdot$ Melanoma

\section{Introduction}

Primary melanomas in early stages are curable by surgery. After metastasis formation, however, patients have a median survival of $<1$ year. Chemotherapy may induce occasional tumor responses [1] but does not improve overall survival. Until 2010, long-term responses in metastatic melanoma were achieved only after adoptive transfer of autologous T cells [2], a therapy applicable to a selected minority of patients with good performance status, or after high dose IL-2 treatment [3].

About $50 \%$ of melanomas express BRAF-activating mutations [4], which are V600E and V600K substitutions in $95 \%$ of cases [5]. Treatment with BRAF inhibitors, MEK inhibitor, or a combination of both prolonged progression-free survival [5-7]. Despite these great advances, patients treated with BRAF or MEK inhibitors experience disease progression after a mean of about 6 months [7]. Recently, the fully humanized anti-CTLA- 4 antibody ipilimumab was reported to increase overall survival of stage III/IV metastatic melanoma patients [8, 9]. The treatment received FDA approval for non-resectable and metastatic 
melanoma in March 2011 [10]. CTLA-4 is expressed on activated T cells, serving as "immune checkpoint" molecule which prevents overwhelming cytotoxicity and consequent autoimmunity and tissue damage. Upon activation, $\mathrm{T}$ cells express CTLA- 4 which binds to its ligands CD80 and CD86 with higher affinity than CD28. Several mechanisms of action have been proposed explaining the strong effect of CTLA-4 blockade [11].

It is well accepted that tumor-reactive $\mathrm{T}$ cells in vivo upregulate CTLA-4. In situ, they show an exhausted, less functional phenotype [12]. Treatment with the CTLA4-blocking antibody ipilimumab increased $\mathrm{T}$ cell activation [13] and their proliferation [14] in stage III/IV melanoma patients. Higher $\mathrm{T}$ cell activation correlates with tumor regression or disease stabilization in about $11-13 \%$ of patients $[8,15]$. However, autoimmune responses are also promoted, as 10-15\% of patients develop severe grade 3-4 immune-related adverse events [8]. Interestingly, these autoimmune manifestations correlate with clinical responses [15].

Tumor lesions may increase in size with the onset of inflammation during ipilimumab treatment, followed by size reductions frequently several months after the completion of ipilimumab dosing [16]. Traditional tumor response criteria are therefore not fully appreciating the clinically relevant effects of anti-CTLA-4 treatment. The new immune-related response criteria take into account that clinical responses can develop late, possibly only after initial tumor mass increase due to inflammation [17]. These criteria have already proven to be highly relevant for oncoimmunological-patient assessments [18], despite that they are not yet fully established for phase III studies. According to these criteria, the first tumor assessment is performed 12 weeks after therapy start.

Identification of biomarkers that are associated with clinical responses to ipilimumab may help to identify patients likely to benefit from the treatment. In bladder cancer, increased frequencies of $\mathrm{CD}^{+}{ }^{+} \mathrm{ICOS}^{\text {high }} \mathrm{T}$ cells correlated with a better clinical outcome [19]. For melanoma, this correlation remains to be confirmed as results are controversial $[14,20]$. Absolute lymphocyte counts after 2 infusions of ipilimumab [18] and the presence of NY-ESO1-specific antibodies and of specific $\mathrm{CD}^{+} \mathrm{T}$ cells [21] correlated positively with clinical outcome in melanoma. Furthermore, high levels of $\mathrm{Ki}^{+}{ }^{+} \mathrm{EOMES}^{+} \mathrm{CD}^{+} \mathrm{T}$ cells were associated with improved relapse-free survival in melanoma patients [14].

While most studies focused on $\mathrm{T}$ cell and antibody responses in patients treated with ipilimumab [13, 14, 20-24], we were particularly interested in studying myeloid cells. In humans, several myeloid-derived suppressor cells (MDSC) subpopulations have been described termed monocytic and granulocytic MDSC, respectively [25-28].
Different malignancies favor the accumulation of different MDSC phenotypes in patients [29]. In melanoma patients, circulating CD14 ${ }^{+}$HLA-DR $^{-}$MDSC were described to be enriched as compared to healthy donors (HD) [30-32]. However, MDSC also vary between different studies of the same cancer type, e.g., human renal cell carcinoma [3335]. MDSC in humans are widely accepted to have low or absent HLA-DR expression [25-28], whereas some experimental mouse models showed that MHC-II expression on MDSC may be important for suppression of $\mathrm{CD}^{+} \mathrm{T}$ cells [36].

In our study of patients treated with CTLA-4-blocking antibody, we hypothesized that improved $\mathrm{T}$ cell activity with stronger proliferation [14] and enhanced cytokine secretion [23] might be paralleled with alterations in the myeloid cell compartment. For example, IFN- $\gamma$ production may play a role because it contributes to MDSC recruitment [37]. Besides the known $\mathrm{T}$ cell intrinsic mechanisms of CTLA-4, several $\mathrm{T}$ cell extrinsic pathways have been described, for instance by competition for co-stimulation via CD80/CD86 (B7), or B7-mediated outside-in-signaling altering myeloid cells, particularly antigen-presenting cells, in their capacity to activate or tolerize immune responses [38]. To obtain more information about mechanisms regulating immune responses in cancer patients, we analyzed MDSC in peripheral blood of advanced melanoma patients receiving the standard regimen of 43 -weekly infusions of ipilimumab $(3 \mathrm{mg} / \mathrm{kg})$. Our results show significant correlations between frequencies of monocytic MDSC and clinical responses in patients treated with ipilimumab.

\section{Materials and methods}

Patient population and study design

Human sample collection and use adhered to protocols approved by the Institutional Review and Privacy Board of the University Hospital of Lausanne (CHUV, Lausanne, Switzerland). All patients gave informed consent prior to study inclusion. We analyzed peripheral blood samples from 49 patients ( 23 females, 26 males), $\geq 18$ years of age and with AJCC stage IV or unresectable stage III malignant melanoma, histologically confirmed (Tables 1,2 ). Fifteen healthy blood donors ( 9 females, 6 males) served as controls (Table 1). Patients treated with ipilimumab (Table 2) had to undergo at least one first-line chemotherapeutic treatment without clinical response before receiving ipilimumab second-line. Patients were treated intravenously with 4 cycles of $3 \mathrm{mg} / \mathrm{kg}$ ipilimumab every 3 weeks. Blood samples were withdrawn at baseline and at 5-time points during the treatment: day 3 after treatment $1(\mathrm{t} 1 \mathrm{~d} 3)$, t1d7, 
Table 1 Characteristics of healthy donors and melanoma patients and their treatment

\begin{tabular}{lc}
\hline Characteristics of patients and healthy donors & Number (range or $\%)$ \\
\hline All patients $(N=49)$ & \\
Median age at blood sample & $63(22-86)$ \\
Gender & \\
Female & $23(47 \%)$ \\
Male & $26(53 \%)$ \\
Patients treated with & \\
No treatment & $23(47 \%)$ \\
Ipilimumab & $15(31 \%)$ \\
Ipilimumab followed by vemurafenib & $1(2 \%)$ \\
Vemurafenib & $10(20 \%)$ \\
Untreated patients $(N=23)$ & \\
Median age at blood sample & $60(22-79)$ \\
Gender & 12 \\
Female & 11 \\
Male & 17 \\
Tumor-bearing patients & 6 \\
Tumor-free patients & $30(13-84)$ \\
Median days after tumor surgery & \\
Study population, i.e., patients treated with ipilimumab \\
monotherapy $(N=15)$
\end{tabular}

The "All patients cohort" $(N=49)$ consist of stage III/IV melanoma patients with different melanoma treatment status. Twenty-three of them did not have had treatment for melanoma except tumor surgery at the time of blood sample and were included into the subgroup analysis for "untreated patients"

Fifteen patients received anti-CTLA-4 treatment and belong to the "study population treated with ipilimumab monotherapy." Remaining patients $(N=11)$ received vemurafenib $(N=10)$ or ipilimumab with subsequent vemurafenib $(N=1)$ and were not analyzed separately. Fifteen HD served as controls

before $\mathrm{t} 3, \mathrm{t} 3 \mathrm{~d} 7$ and $\mathrm{t} 4 \mathrm{~d} 20$. Follow-up blood samples were obtained after 3-30 months post-treatment.

\section{Calculation of MDSC frequencies}

Whenever multiple blood samples were withdrawn from a patient during the course of treatment and follow-up, the average frequency per patient is given and indicated as such
Table 2 Clinical details of melanoma patients treated with ipilimumab

\begin{tabular}{ll}
\hline Characteristics of patients treated with & Number of patients \\
ipilimumab monotherapy $(N=15)$ & \\
\hline Number of ipilimumab infusions & \\
2 & $1(7 \%)$ \\
3 & $2(13 \%)$ \\
4 & $12(80 \%)$ \\
Number of blood samples per patient during treatment and \\
follow-up \\
1 \\
2 \\
3
\end{tabular}

$P R$ partial response, $C R$ complete response, $S D$ stable disease, $P D$ progressive disease, $L D H$ serum lactate dehydrogenase

in the figure legends. The finding that MDSC values per patient do not change significantly over time makes average values meaningful. Otherwise, the indicated MDSC frequency corresponds to one blood sample per patient.

\section{Assessment of clinical responses}

Tumor response was assessed at week 12, 16 and/or 24 following treatment with ipilimumab using the immunerelated response criteria [17]. Patients achieving complete responses (CR), partial responses (PR) or stable disease (SD) at week 12 or 16/24 post-ipilimumab were considered 
responders (R). Patients with progressive disease until week $16 / 24$ post-ipilimumab were considered non-responders (NR).

\section{LDH measurement}

Serum lactate dehydrogenase (LDH) enzyme levels were judged increased if above $225 \mathrm{U} /$ l, i.e., the institutional upper limit.

\section{PBMC purification}

Blood samples were withdrawn using tubes containing Li-heparin-coated beads (Sarstedt cat. no. 02.1065). Blood was centrifuged for $10 \mathrm{~min}$ at $1,500 \mathrm{rpm}$ for plasma preservation and afterward PBMC were purified by density gradient centrifugation using Lymphoprep (Axis-Shield cat no. 1114547). Monocytic MDSC are enriched in the mononuclear cell layer; therefore, we did not perform whole blood stainings. All blood processing was performed within $3 \mathrm{~h}$ after blood withdrawal, and PBMC were used for flow cytometric analysis without cryopreservation.

\section{Flow cytometry and antibodies}

Freshly purified PBMC were incubated with human Fc receptor-blocking reagent (Miltenyi cat. no. 130-059-901) before staining with monoclonal antibodies against human CD3 (PE-labeled, BD cat. no. 345765), CD14 (Pacific blue-labeled, BD cat. no. 558121), CD19 (PE-labeled, Beckman Coulter cat. no. 6603024), CD56 (PE-labeled, BD cat. no. 345810), CTLA-4 (APC-labeled, BD cat no. 555855), HLA-DR (ECD labeled, Beckman Coulter cat. no. IM3636), HLA-DR (PerCP-Cy5.5-labeled, Biolegend cat. no. 307630) and IL-4R-alpha (APC-labeled, R\&D cat no. FAB230A) or IgG2-alpha isotype control (APClabeled, R\&D cat no. IC003A). Dead cells were detected with vivid fixable live dead marker (near IR) (Invitrogen cat. no. L10119). Data were acquired on a Gallios flow cytometer (Beckman Coulter) and analyzed using FlowJo 9.1 (TreeStar).

\section{Statistical analysis}

Statistical analyses were performed by GraphPad Prism 5 software using parametric $t$ test. When comparing samples of the same patient before and after treatment initiation, a paired- $t$ test was used (Fig. 3b). A value of $p<0.05$ was considered statistically significant. Results from multiple samples per patient (dependent values) were analyzed using Bonferroni correction (Fig. 3a). A value of $p<0.01$ was considered statistically significant.

\section{Results}

Patients

The present study analyzed 49 malignant melanoma patients between September 2010 and October 2012. Fifteen healthy blood donors served as controls. The characteristics of the HD and patients as well as their treatment are provided in Table 1. Fifteen of the patients received ipilimumab treatment with 4 cycles of $3 \mathrm{mg} / \mathrm{kg}$ every 3 weeks. Details of ipilimumab-treated patients, their treatments and the blood samples obtained are summarized in Table 2.

MDSC are significantly enriched in melanoma patients

In order to study whether anti-CTLA-4 therapy has any effects on monocytic MDSC recruitment and whether MDSC are associated with therapeutic outcome, we characterized monocytic MDSC in stage III and IV melanoma patients.

First, we asked the question whether MDSC are enriched in melanoma patients compared to healthy individuals, regardless of treatment received (Table 1, "All patients" section). In order to thoroughly assess MDSC, we set up a flow cytometry panel covering markers for human myeloid cells (suppl. Fig. 1). By gating, we excluded lineage positive $\left(\mathrm{CD}^{+}, \mathrm{CD} 19^{+}\right.$and $\left.\mathrm{CD} 56^{+}\right)$cells, doublet and dead cells. We observed significantly more HLA-DR ${ }^{-}$cells among monocytic $\mathrm{CD} 14^{+}$cells from melanoma patients compared to HD (Fig. 1a-c, $* p<0.05$ ). As this melanoma patient cohort received different treatments, they are marked in the figure legend. The gate for HLA-DR ${ }^{-}$cells was set individually for each donor according to the reference gates drawn (suppl. Fig. 1).

Despite that we were able to recruit several elderly $\mathrm{HD}$, it was not enough to reach a fully matched age distribution between HD and patients. However, there was no age-dependent alteration of monocytic MDSC frequency (suppl. Fig. 2). In an attempt to more precisely match both cohorts, we subtracted the HD and patients younger than 32 from the analysis, resulting in a median age of 50 years for $\mathrm{HD}$ and 63 years for patients. Again, the frequencies of monocytic MDSC were significantly higher in patients compared to HD (suppl. Fig. 3).

The lin $^{-}$CD $14^{+}$HLA-DR ${ }^{-}$cells were then tested with an antibody specific for IL-4R-alpha (CD124). In patients as well as HD, we observed CD124 expression (suppl. Fig. 4).

Chemotherapy or cytokine-based therapies might influence MDSC generation and recruitment or lead to further maturation of these cells in vivo [31,39-42]. Therefore, we performed a subgroup analysis in patients that received no treatment except tumor surgery. We found a trend toward 


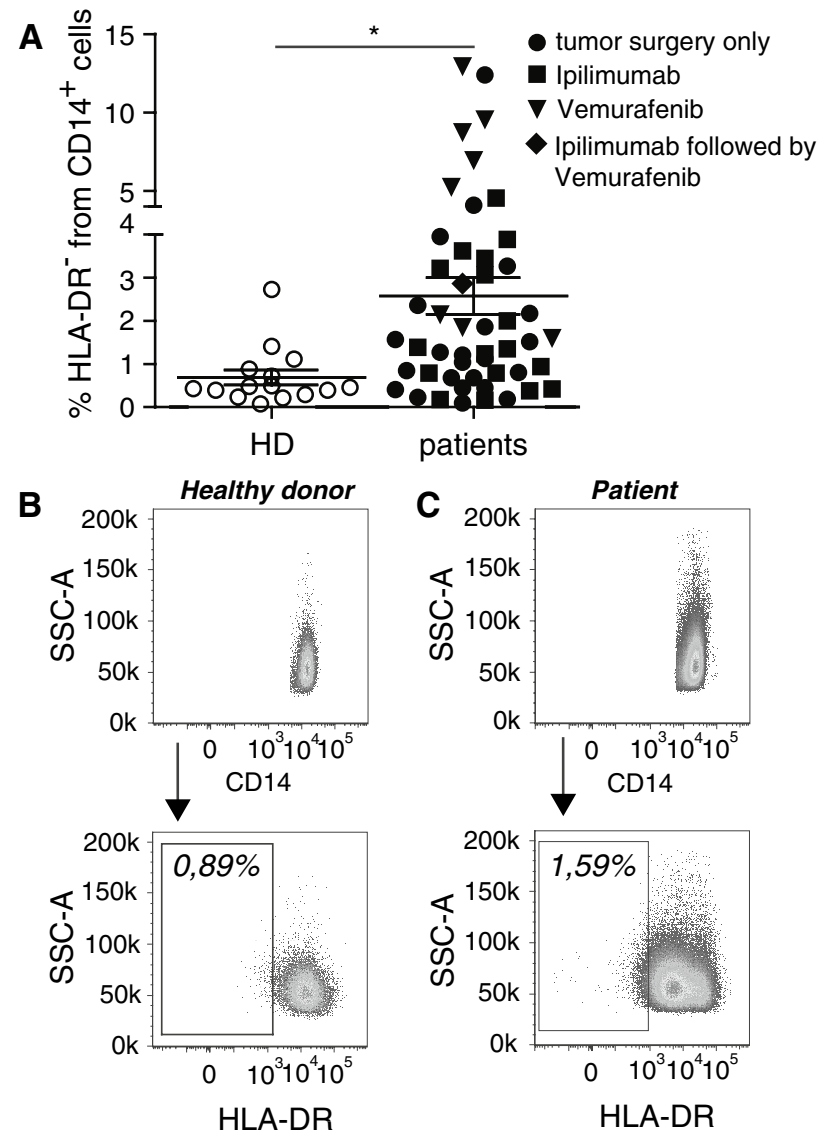

Fig. 1 MDSC frequencies are increased in patients with melanoma. PBMC from healthy donors and melanoma patients were assessed by flow cytometry. a $\% \operatorname{lin}^{-} \mathrm{CD}_{1} 4^{+} \mathrm{HLA}^{-D R^{-}}$cells (monocytic MDSC) in healthy donors (HD; $0.69 \pm 0.67 \%, N=15)$ and melanoma patients $(2.57 \pm 2.97 \%, N=49)$. Symbols in the figure correspond to either 1 blood sample per patient or the average frequency from several blood samples obtained per patient. Melanoma treatments received: tumor surgery only (circles), ipilimumab (squares), vemurafenib (triangles), ipilimumab followed by vemurafenib (diamonds). b Representative dot plots for one healthy donor and $\mathbf{c}$ one melanoma patient. $* p<0.05$

the enrichment of $\operatorname{lin}^{-} \mathrm{CD} 14^{+} \mathrm{HLA}^{-\mathrm{DR}}{ }^{-}$cells in patients prior to treatment when compared to HD (Fig. 2a), mainly due to smaller sample numbers available. Furthermore, we observed a trend for accumulation of $\mathrm{lin}^{-} \mathrm{CD} 14^{+} \mathrm{HLA}-$ $\mathrm{DR}^{-}$cells in peripheral blood of tumor-bearing patients compared to patients after tumor resection (Fig. 2b), without reaching statistical significance.

MDSC frequencies are not modified by ipilimumab treatment, do not depend on baseline LDH levels, but tend to differ between metastatic sub stages

We analyzed $\operatorname{lin}^{-} \mathrm{CD} 14^{+} \mathrm{HLA}^{-\mathrm{DR}^{-}}$monocytic MDSC at baseline and over several time points during and after ipilimumab treatment. We did not observe significant changes in frequencies of lin $^{-}$CD14 ${ }^{+}$HLA-DR $^{-}$cells (Fig. 3a, b). Suppl. Fig. 5 shows MDSC frequencies at baseline and during treatment for seven representative patients, i.e., the ones of whom baseline samples were available. Responders and NR are marked in the legend. Staining of monocytic cells with anti-CTLA- $4 \mathrm{mAb}$ was negative for $\mathrm{HD}$ and patients (suppl. Fig. 6), speaking against a direct effect of ipilimumab treatment on this cell population.

Since serum LDH correlates with tumor burden in advanced melanoma, we asked whether patients presenting with an increased serum LDH level before treatment accumulate higher numbers of MDSC. Our results showed no significant difference in overall frequency of lin $^{-}$CD $14^{+}$HLA-DR $^{-}$cells among patients with normal versus high serum LDH level at baseline (Fig. 3c). When comparing baseline frequencies of MDSC with the corresponding baseline $\mathrm{LDH}$ values, also no correlation was found ( $p=0.21$, data not shown). Finally, we addressed the question, whether the metastatic substage (stage IV M1a vs. M1b vs. M1c) had any impact on the accumulation of MDSC. We observed a trend toward less $\operatorname{lin}^{-}$ CD14 ${ }^{+}$HLA-DR $^{-}$cells in patients having distant metastasis in the skin or lymph nodes only (stage IV M1a) compared to patients having distant metastasis in other vital organs or increased LDH (stage IV M1c) (Fig. 3d $p=0.069)$. M1a stage patients showed $\operatorname{lin}^{-} \mathrm{CD} 14^{+}$HLA$\mathrm{DR}^{-}$cell frequencies comparable to $\mathrm{HD}$. Of note, there was a subpopulation of patients with M1b and M1c stage disease who were mostly clinical NR with increased frequencies of $\operatorname{lin}^{-} \mathrm{CD} 14^{+}$HLA-DR ${ }^{-}$MDSC. In the next step, we analyzed clinical responders and non-responders separately $(* * * p<0.001)$.

Low frequencies of MDSC are associated with clinical responses to ipilimumab treatment

About $11-13 \%$ of patients treated with ipilimumab achieve objective tumor responses [8, 15]. CR, PR and stabilization of disease (SD) were reported [8]. Responding patients are shown to have a significantly augmented $\mathrm{T}$ cell frequency, activity and function [13, 22, 24, 43]. So far, several biomarkers are published to correlate with clinical outcome after ipilimumab treatment $[14,18,19,21]$. Most studies focused on T cell-mediated effects of ipilimumab. As T cell extrinsic pathways via CD80/CD86 may be also targeted by ipilimumab treatment, we focused on myeloid cell kinetics during ipilimumab treatment. Interestingly, our data revealed significantly lower percentages of $\operatorname{lin}^{-} \mathrm{CD} 14^{+}$ HLA-DR ${ }^{-}$MDSC in patients responding to ipilimumab treatment compared to NR (Fig. $4 \mathrm{a},{ }^{*} p<0.05$ ). When comparing baseline values with average values during and after ipilimumab treatment, we found a trend of lower values in responders as compared to NR (Fig. 4b). However, patient 
A

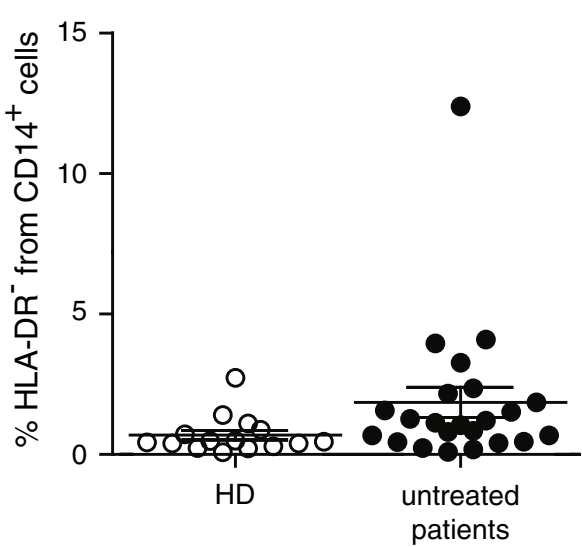

Fig. 2 MDSC in untreated patients with and without active diseases. PBMC from healthy donors and untreated melanoma patients were assessed by flow cytometry. a $\% \operatorname{lin}^{-} \mathrm{CD} 14^{+} \mathrm{HLA}^{-D R^{-}}$cells in $\mathrm{HD}(0.69 \pm 0.67 \%, N=15)$ and non-treated melanoma patients
B

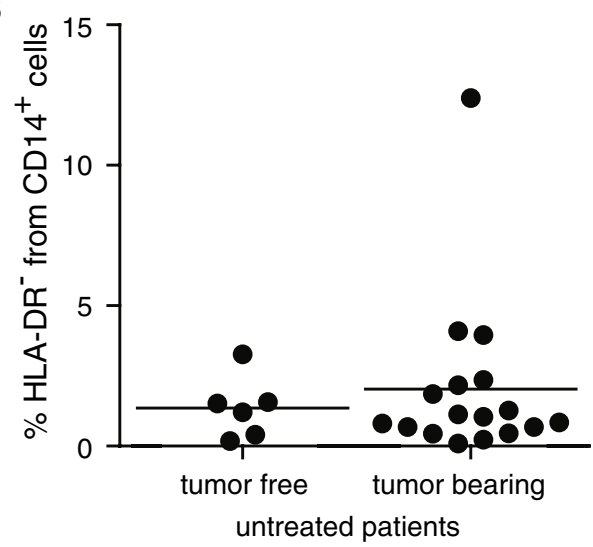

$(1.86 \pm 2.56 \%, N=23)$. b $\% \operatorname{lin}^{-} \mathrm{CD}^{+} 4^{+} \mathrm{HLA}_{-\mathrm{DR}}^{-}$cells in untreated patients after tumor resection $(1.36 \pm 1.10 \%, N=6)$ and untreated patients with tumor burden $(2.03 \pm 2.92 \%, N=17)$. Symbols in the figure correspond to 1 blood sample per patient
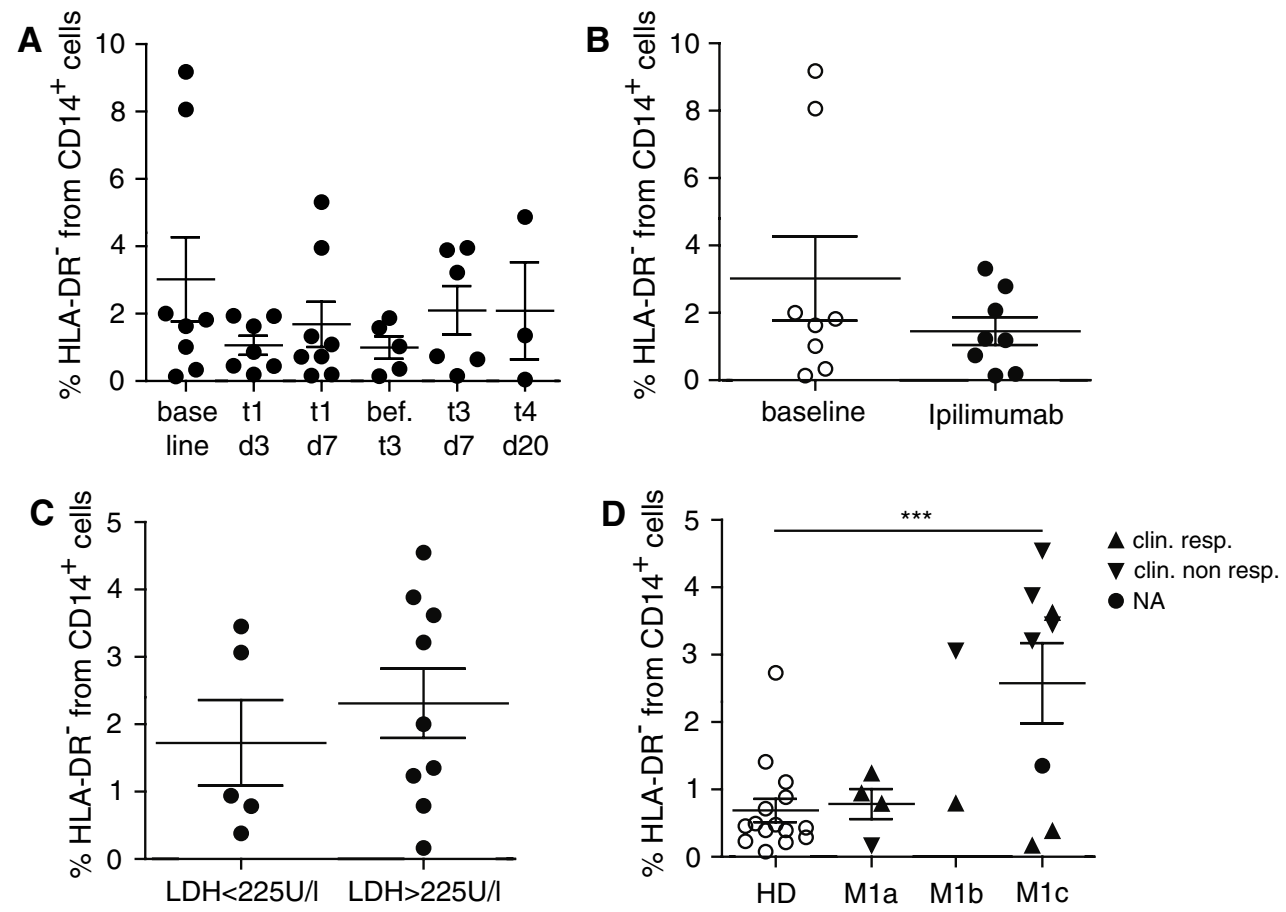

Fig. 3 MDSC in ipilimumab-treated patients and in patients with different disease stages. PBMC from melanoma patients receiving ipilimumab treatment were assessed by flow cytometry. a \% $\operatorname{lin}^{-} \mathrm{CD} 14^{+}$ $\mathrm{HLA}_{-} \mathrm{DR}^{-}$cells in melanoma patients receiving ipilimumab treatment. MDSC frequencies are displayed for each day of blood withdrawal: baseline $3.02 \pm 3.53 \%(N=8), \mathrm{t} 1 \mathrm{~d} 31.07 \pm 0.75 \%(N=7)$, t1d7 $1.69 \pm 1.90 \%(N=8)$, before t3 $1.00 \pm 0.75 \%(N=5), \mathrm{t} 3 \mathrm{~d} 7$ $2.10 \pm 1.77 \%(N=6)$ and $\mathrm{t} 4 \mathrm{~d} 202.09 \pm 2.50 \%(N=3)$. b MDSC frequencies are displayed at baseline $(3.02 \pm 3.53 \%, N=8)$ and during/after treatment $(1.46 \pm 1.17 \%, N=8)$. c $\% \operatorname{lin}^{-} \mathrm{CD} 14^{+}$

HLA-DR $^{-}$cells in ipilimumab-treated patients with normal baseline serum LDH level $(1.73 \pm 1.42 \%, N=5)$ and elevated baseline serum LDH level $(2.31 \pm 1.55 \%, N=9)$. d $\% \operatorname{lin}^{-}$CD14 ${ }^{+}$HLA$\mathrm{DR}^{-}$cells in $\mathrm{HD}(0.69 \pm 0.67 \%, N=15)$ and ipilimumab-treated patients with metastatic staging M1a $(0.78 \pm 0.45 \%, N=4), \mathrm{M} 1 \mathrm{~b}$ $(N=2)$ and M1c $(2.58 \pm 1.69 \%, N=8)$. Symbols in the figure correspond to either 1 blood sample per patient or the average frequency from several blood samples obtained per patient. Clinical responder (triangle upward) and clinical non-responder (triangle downward). $* * * p<0.001$. $L D H$ serum lactate dehydrogenase 

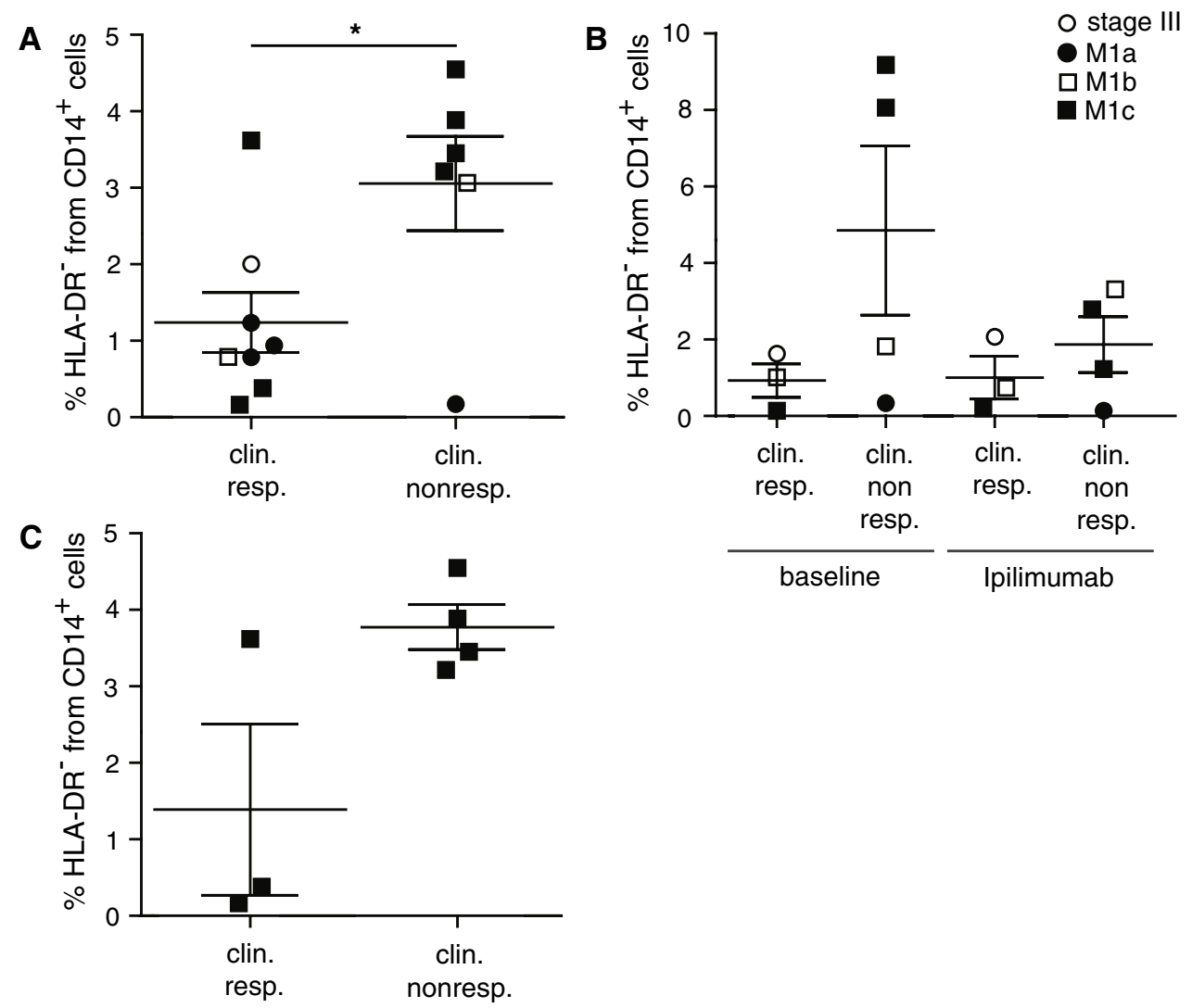

Fig. 4 MDSC in patients responding or non-responding to ipilimumab treatments. PBMC from melanoma patients receiving ipilimumab treatment were assessed by flow cytometry. a $\% \operatorname{lin}^{-}$ $\mathrm{CD}_{14}{ }^{+} \mathrm{HLA}^{-D R^{-}}$cells in ipilimumab-treated patients responding $(1.24 \pm 1.11 \%, N=8)$ or non-responding $(3.06 \pm 1.51 \%, N=6)$ to the treatment. b Baseline levels of $\%$ lin $^{-} \mathrm{CD} 14^{+} \mathrm{HLA}^{-D R^{-}}$cells for clinical responders $(0.93 \pm 0.75 \%, N=3)$ and clinical nonresponders $(4.85 \pm 4.42 \%, N=4)$ and frequencies during treatment

numbers were small, and the differences were not statistically significant, precluding conclusions.

Of note, we detected higher frequencies of $\operatorname{lin}^{-} \mathrm{CD} 14^{+}$ HLA-DR $^{-}$cells in patients with higher metastatic burden (Fig. 3d). This could be associated with bad clinical outcome and thus introduce a bias in our data analysis. However, both the responder as well as the non-responder group contained stage M1a, M1b and M1c patients (Fig. 4a, b). When focusing exclusively on samples from patients with high metastatic load (stage IV M1c), we detected a trend toward lower frequencies of monocytic $\operatorname{lin}^{-} \mathrm{CD} 14^{+}$HLA$\mathrm{DR}^{-}$cells in ipilimumab responders as compared to NR (Fig. $4 \mathrm{c}, p=0.062$ ), however, without reaching statistical significance, likely due to small sample numbers.

Overall, our data show accumulation of monocytic MDSC in melanoma patients. Frequencies of monocytic MDSC tended to increase with metastatic spread. More importantly, frequencies of monocytic MDSC in melanoma patients correlated with their clinical response to

for clinical responders $(1.00 \pm 0.97 \%, N=3)$ and non-responders $(1.87 \pm 1.45 \%, N=4)$. c $\%$ lin $^{-} \mathrm{CD} 4^{+} \mathrm{HLA}^{-\mathrm{DR}^{-}}$cells in ipilimumab-treated patients with distant metastasis (M1c) responding $(1.39 \pm 1.94 \%, N=3)$ or non-responding $(3.77 \pm 0.59 \%, N=4)$ to the treatment. Symbols in the figure correspond to either 1 blood sample per patient or the average frequency from several blood samples obtained per patient. ${ }^{*} p<0.05$

ipilimumab treatment, which should be validated in following studies including larger patient cohorts.

\section{Discussion}

In the present study, we set out to perform a detailed flow cytometry analysis of MDSC in patients with cutaneous melanoma, with a special focus on potential effects of antiCTLA-4 therapy consisting of 43 -weekly cycles of ipilimumab (Yervoy ${ }^{\circledR}$ ) at $3 \mathrm{mg} / \mathrm{kg}$. In order to avoid in vitro artifacts due to freezing-thawing procedures and delayed blood processing, we analyzed fresh blood samples directly after withdrawal. We optimized the analysis for monocytic MDSC by using PBMC prepared with conventional density gradient centrifugation, as MDSC are purified together with mononuclear cells. This procedure is an alternative to whole blood stainings, where a higher background due to less pure cell fractions is a common obstacle. 
In concordance with the literature, we found that monocytic $\operatorname{lin}^{-} \mathrm{CD}^{+} 4^{+} \mathrm{HLA}^{-} \mathrm{DR}^{-}$MDSC were significantly enriched in PBMC from melanoma patients compared to HD [30-32]. This difference occurred only as a trend when comparing HD and untreated patients, likely because fewer samples were available from untreated patients. As some of the vemurafenib-treated patients show higher frequencies of $\operatorname{lin}^{-} \mathrm{CD} 14^{+} \mathrm{HLA}^{-\mathrm{DR}^{-}}$cells, we cannot exclude a possible relationship between this treatment and high MDSC frequencies. We did not have enough patients and samples to follow this trend, but, most importantly, vemurafenib patients do not account for the significant difference in frequencies of $\operatorname{lin}^{-} \mathrm{CD} 14^{+} \mathrm{HLA}_{-} \mathrm{DR}^{-}$cells in melanoma patients and HD, as this difference remains significant when vemurafenib-treated patients were excluded from the analysis. Confirming our results, Mandruzzato et al. [44] identified IL-4R-alpha expression on monocytic cells enriched in cancer patients compared to healthy controls, but as opposed to our data no HLA-DR expression was assessed.

We observed a trend pointing toward enrichment of monocytic MDSC in patients with tumor burden, compared to tumor-free patients. In line with this, for patients with non-active disease, reduced frequencies of $\mathrm{CD} 14^{+}$HLA$\mathrm{DR}^{-}$MDSC have been described for melanoma patients and of $\mathrm{CD}_{14}{ }^{-} \mathrm{CD} 33^{+} \mathrm{CD} 11 \mathrm{~b}^{+}$MDSC for patients with breast cancer [30, 45].

So far, very few is known about MDSC frequencies in melanoma patients treated with ipilimumab. It is important to study how MDSC behave in the context of an environment with increased $\mathrm{T}$ cell activity, in order to estimate drug-induced changes in the myeloid cell compartment of patients. For example, $\mathrm{T}$ cells from ipilimumab-treated patients secrete higher amounts of IFN- $\gamma$ [23] which is known to recruit MDSC [37]. Therefore, one could expect that ipilimumab-treated patients accumulate higher MDSC frequencies. In contrast, our data show no significant differences in MDSC frequencies over time in ipilimumabtreated patients, indicating that these cells are tightly regulated. In contrast, the patient-to-patient variability was high, even among patients with the same tumor staging.

When testing the potential of ipilimumab as neoadjuvant in stage III b-c patients, a drop of MDSC frequencies 6 weeks after treatment induction was reported [46]. Furthermore, Tarhini et al. have analyzed several MDSC subsets in melanoma patients receiving the anti-CTLA-4 antibody tremelimumab together with IFN- $\alpha$. In contrast to our study, a decrease in frequency of monocytic MDSC was seen at days 29 and 85 [47] when cryopreserved samples were used. We analyzed fresh PBMC, immediately after blood withdrawal from patients and healthy controls, because our results with cryopreserved cells were inconsistent (manuscript in preparation). Besides technical differences, there are further reasons why the studies are not directly comparable. For example, different ipilimumab dosing was used in the neoadjuvant study, and antiCTLA-4 therapy was conducted in combination with IFN- $\alpha$ in the tremelimumab study.

Most probably, $\mathrm{T}$ effector and $\mathrm{T}$ regulatory cells are the most direct targets of anti-CTLA-4 therapy. However, CTLA-4 expression has been observed in small quantities on the surface and more pronounced intracellular in monocytes [48, 49], suggesting that ipilimumab could eventually act on monocytes or MDSC directly. Comin-Anduix et al. reported changes in the phosphorylation status of p38, ERK1/2, Stat-1, Stat-3 and Stat-5 in monocytes of patients treated with the anti-CTLA-4 antibody tremelimumab. Furthermore, monocytes of clinical responders and NR to tremelimumab differed in phosphorylation levels of Akt and Stat-6 [49]. In contrast to these observations, our study did not reveal CTLA-4 expression on monocytic cells and also no changes of MDSC frequencies were induced by ipilimumab treatment.

We did not find any correlation between serum LDH levels at baseline and accumulation of MDSC in blood of melanoma patients. If MDSC recruitment is altered in patients with higher serum LDH levels, reflecting strongly progressive disease, this might take place only in the tumor microenvironment, remaining undetectable in the blood.

Patients with bulky metastatic disease (M1c) showed a trend toward higher frequencies of monocytic MDSC than patients with metastases limited to skin and/or lymph nodes (M1a). For the more immature MDSC population of $\operatorname{lin}^{-}$ $\mathrm{CD}_{3}{ }^{+} \mathrm{CD}_{11 \mathrm{~b}^{+}}$cells, this correlation has been described already in a patient cohort comprising of different malignancies [50]. Interestingly, in our study, patients with stage IV M1a metastatic disease showed MDSC levels comparable to $\mathrm{HD}$, indicating that MDSC increased only later, i.e., with tumor spread to visceral sites, beyond skin and lymph nodes. This might involve tumor secreted VEGF, known to play a role in MDSC recruitment [51]. Possibly, higher amounts of MDSC might facilitate metastasis formation, e.g., by creating an immunosuppressive environment.

When distinguishing clinical responders and nonresponders within the different metastatic stages, we identified a subgroup of M1b and M1c patients. These patients had higher frequencies of monocytic MDSC and were mostly clinical non-responders. The subsequent analysis of clinical responders and non-responders addressed this effect.

Clinical benefit of ipilimumab treatment can take months to develop. Initially, tumor lesions might even increase in size due to local recruitment of immune cells and inflammation [16]. Therefore, the tumor response evaluation by standard RECIST criteria at week 12 after treatment may not reflect actual anti-tumor activity. As recommended 
recently, we applied the immune-modified RECIST criteria [17] and evaluated the tumor response by CT scans performed at week 12, 16 and/or 24 after treatment. Our immune monitoring of patients treated with ipilimumab focused on identifying biomarkers associated with clinical response, with the aim of finding predictive markers. Our data show for the first time that MDSC frequency in PBMC of melanoma patients with ipilimumab treatment correlates significantly with the patient's clinical response. This is also observed as a trend in patients with highly aggressive bulky metastatic disease (M1c), whose treatment options were very limited before the introduction of ipilimumab.

In contrast to our study, the frequency of the more immature lin $^{-} \mathrm{HLA}^{-} \mathrm{DR}^{-} \mathrm{CD} 33^{+} \mathrm{CD}^{-} 1 \mathrm{~b}^{+} \mathrm{MDSC}$ was reported to decrease stronger in patients responding to tremelimumab in combination with IFN- $\alpha$ [47]. For the reasons mentioned above (different patient treatments, different laboratory techniques), the results of the studies cannot be compared directly.

It has been shown previously that patients with high baseline expression levels of immune-related genes and an immune-active tumor microenvironment in tumor tissue are more likely to respond favorably to ipilimumab [52]. Our data on peripheral blood are in line with this observation, as they show that patients with low frequencies of MDSC, implying less immune suppression and better reactivity, have improved clinical outcome.

Recently, a correlation between the frequency of CD14 ${ }^{+}$ HLA-DR ${ }^{-}$cells and overall survival could be detected in renal cell carcinoma patients [53]. Furthermore, frequencies of lin $^{-} \mathrm{HLA}^{-D R^{-}} \mathrm{CD}^{+} 3^{+} \mathrm{CD}_{11 b^{+}}$MDSC correlated with overall survival in patients with pancreatic and esophagogastric cancer [54]. In contrast, our data did not reveal significant correlations between MDSC frequencies and overall survival. To our knowledge, we provide the first evidence that MDSC frequencies in PBMC correlate with clinical response to treatment with ipilimumab. Although our study was retrospective and involving a relatively small number of patients, it suggests that MDSC frequencies correlate with outcome of anti-CTLA-4 treatment. Prospective clinical trials assessing MDSC subpopulations and frequencies as potential biomarkers of response to CTLA-4 blockade are therefore warranted to validate our observations.

\footnotetext{
Acknowledgments We are obliged to the patients and blood donors for their dedicated collaboration. We thank Maurice Matter, Laurence de Leval, Ivan Letovanec, Pu Yan, Gregoire Berthod, Stephane Badel, Hasna Bouchaab, Guillaume Buss, Alexandre Christinat, Florian Claude, Nathalie Divorne, Mauro Figeri, Mathilde Gavillet, Athina Stravodimou, Donatienne Taylor, Evangelia Tzika, JeanPhilippe Zuercher, Pedro Romero, Nathalie Rufer, Laurent Derré, Samia Abed-Maillard, Lukas Baitsch, Natacha Bordry, Marion Braun, Silvia Fuertes-Marraco, Philippe Gannon, Bhawna Gupta, Michaël Hebeisen, Agnès Hiou, Marina Iancu, Kalliopi Ioannidou, Camilla Jandus, Danny Labes, Luc Lebon, Amandine Legat, Tanja Lövgren,
}

Alexandra Michel, Faiza Mourali-Ayari, Timothy Murray, Natalie Neubert, Eran Ophir, Danilo Presotto, Jean-Paul Rivals, Godehard Scholz, Alexandre Wicky and Sintia Winkler for collaboration and advice and Martine van Overloop for administrative assistance. We thank Mohamed Faouzi and Pierluigi Ballabeni for help with statistics. This work was supported by Ludwig Cancer Research, the Cancer Vaccine Collaborative, the CRI (all NY, USA), the ISREC Foundation, the Swiss National Science Foundation (310030_135553 and CRSII3_141879), and the Swiss Cancer League (02836-08-2011).

Conflict of interest The authors declare no conflict of interest.

\section{References}

1. Garbe C, Eigentler TK, Keilholz U, Hauschild A, Kirkwood JM (2011) Systematic review of medical treatment in melanoma: current status and future prospects. Oncologist 16(1):5-24

2. Rosenberg SA, Dudley ME (2009) Adoptive cell therapy for the treatment of patients with metastatic melanoma. Curr Opin Immunol 21(2):233-240

3. Atkins MB, Lotze MT, Dutcher JP, Fisher RI, Weiss G, Margolin K, Abrams J, Sznol M, Parkinson D, Hawkins M, Paradise C, Kunkel L, Rosenberg SA (1999) High-dose recombinant interleukin 2 therapy for patients with metastatic melanoma: analysis of 270 patients treated between 1985 and 1993. J Clin Oncol 17(7):2105-2116

4. Sosman JA, Kim KB, Schuchter L, Gonzalez R, Pavlick AC, Weber JS, McArthur GA, Hutson TE, Moschos SJ, Flaherty KT, Hersey P, Kefford R, Lawrence D, Puzanov I, Lewis KD, Amaravadi RK, Chmielowski B, Lawrence HJ, Shyr Y, Ye F, Li J, Nolop KB, Lee RJ, Joe AK, Ribas A (2012) Survival in BRAF V600mutant advanced melanoma treated with vemurafenib. $\mathrm{N}$ Engl $\mathrm{J}$ Med 366(8):707-714

5. Flaherty KT, Robert C, Hersey P, Nathan P, Garbe C, Milhem M, Demidov LV, Hassel JC, Rutkowski P, Mohr P, Dummer R, Trefzer U, Larkin JM, Utikal J, Dreno B, Nyakas M, Middleton MR, Becker JC, Casey M, Sherman LJ, Wu FS, Ouellet D, Martin AM, Patel K, Schadendorf D (2012) Improved survival with MEK inhibition in BRAF-mutated melanoma. N Engl J Med 367(2):107-114

6. Chapman PB, Hauschild A, Robert C, Haanen JB, Ascierto P, Larkin J, Dummer R, Garbe C, Testori A, Maio M, Hogg D, Lorigan P, Lebbe C, Jouary T, Schadendorf D, Ribas A, O'Day SJ, Sosman JA, Kirkwood JM, Eggermont AM, Dreno B, Nolop K, Li J, Nelson B, Hou J, Lee RJ, Flaherty KT, McArthur GA (2011) Improved survival with vemurafenib in melanoma with BRAF V600E mutation. N Engl J Med 364(26):2507-2516

7. Flaherty KT, Infante JR, Daud A, Gonzalez R, Kefford RF, Sosman J, Hamid O, Schuchter L, Cebon J, Ibrahim N, Kudchadkar R, Burris HA 3rd, Falchook G, Algazi A, Lewis K, Long GV, Puzanov I, Lebowitz P, Singh A, Little S, Sun P, Allred A, Ouellet D, Kim KB, Patel K, Weber J (2012) Combined BRAF and MEK inhibition in melanoma with BRAF V600 mutations. N Engl J Med 367(18):1694-1703

8. Hodi FS, O'Day SJ, McDermott DF, Weber RW, Sosman JA, Haanen JB, Gonzalez R, Robert C, Schadendorf D, Hassel JC, Akerley W, van den Eertwegh AJ, Lutzky J, Lorigan P, Vaubel JM, Linette GP, Hogg D, Ottensmeier CH, Lebbe C, Peschel C, Quirt I, Clark JI, Wolchok JD, Weber JS, Tian J, Yellin MJ, Nichol GM, Hoos A, Urba WJ (2010) Improved survival with ipilimumab in patients with metastatic melanoma. N Engl J Med 363(8):711-723

9. Robert C, Thomas L, Bondarenko I, O'Day S, M D J, Garbe C, Lebbe C, Baurain JF, Testori A, Grob JJ, Davidson N, Richards J, Maio M, Hauschild A, Jr Miller WH, Gascon P, Lotem 
M, Harmankaya K, Ibrahim R, Francis S, Chen TT, Humphrey R, Hoos A, Wolchok JD (2011) Ipilimumab plus dacarbazine for previously untreated metastatic melanoma. N Engl J Med 364(26):2517-2526

10. Sondak VK, Smalley KS, Kudchadkar R, Grippon S, Kirkpatrick P (2011) Ipilimumab. Nat Rev Drug Discov 10(6):411-412

11. Pardoll DM (2012) The blockade of immune checkpoints in cancer immunotherapy. Nat Rev Cancer 12(4):252-264

12. Baitsch L, Baumgaertner P, Devevre E, Raghav SK, Legat A, Barba L, Wieckowski S, Bouzourene H, Deplancke B, Romero P, Rufer N, Speiser DE (2011) Exhaustion of tumor-specific CD8+ $\mathrm{T}$ cells in metastases from melanoma patients. J Clin Invest 121(6):2350-2360

13. Weber JS, Hamid O, Chasalow SD, Wu DY, Parker SM, Galbraith S, Gnjatic S, Berman D (2011) Ipilimumab increases activated T cells and enhances humoral immunity in patients with advanced melanoma. J Immunother 35(1):89-97

14. Wang W, Yu D, Sarnaik AA, Yu B, Hall M, Morelli D, Zhang Y, Zhao X, Weber JS (2012) Biomarkers on melanoma patient $\mathrm{T}$ cells associated with ipilimumab treatment. J Transl Med 10(1):146-158

15. Attia P, Phan GQ, Maker AV, Robinson MR, Quezado MM, Yang JC, Sherry RM, Topalian SL, Kammula US, Royal RE, Restifo NP, Haworth LR, Levy C, Mavroukakis SA, Nichol G, Yellin MJ, Rosenberg SA (2005) Autoimmunity correlates with tumor regression in patients with metastatic melanoma treated with anti-cytotoxic T-lymphocyte antigen-4. J Clin Oncol 23(25):6043-6053

16. Hwu P (2010) Treating cancer by targeting the immune system. N Engl J Med 363(8):779-781

17. Wolchok JD, Hoos A, O'Day S, Weber JS, Hamid O, Lebbe C, Maio M, Binder M, Bohnsack O, Nichol G, Humphrey R, Hodi FS (2009) Guidelines for the evaluation of immune therapy activity in solid tumors: immune-related response criteria. Clin Cancer Res 15(23):7412-7420

18. Ku GY, Yuan J, Page DB, Schroeder SE, Panageas KS, Carvajal RD, Chapman PB, Schwartz GK, Allison JP, Wolchok JD (2010) Single-institution experience with ipilimumab in advanced melanoma patients in the compassionate use setting: lymphocyte count after 2 doses correlates with survival. Cancer 116(7):1767-1775

19. Carthon BC, Wolchok JD, Yuan J, Kamat A, Ng Tang DS, Sun J, Ku G, Troncoso P, Logothetis CJ, Allison JP, Sharma P (2010) Preoperative CTLA-4 blockade: tolerability and immune monitoring in the setting of a presurgical clinical trial. Clin Cancer Res 16(10):2861-2871

20. Di Giacomo AM, Calabro L, Danielli R, Fonsatti E, Bertocci E, Pesce I, Fazio C, Cutaia O, Giannarelli D, Miracco C, Biagioli M, Altomonte M, Maio M (2013) Long-term survival and immunological parameters in metastatic melanoma patients who responded to ipilimumab $10 \mathrm{mg} / \mathrm{kg}$ within an expanded access programme. Cancer Immunol Immunother 62(6):1021-1028

21. Yuan J, Adamow M, Ginsberg BA, Rasalan TS, Ritter E, Gallardo HF, Xu Y, Pogoriler E, Terzulli SL, Kuk D, Panageas KS, Ritter G, Sznol M, Halaban R, Jungbluth AA, Allison JP, Old LJ, Wolchok JD, Gnjatic S (2011) Integrated NY-ESO-1 antibody and CD8 + T-cell responses correlate with clinical benefit in advanced melanoma patients treated with ipilimumab. Proc Natl Acad Sci USA 108(40):16723-16728

22. Yuan J, Ginsberg B, Page D, Li Y, Rasalan T, Gallardo HF, Xu Y, Adams S, Bhardwaj N, Busam K, Old LJ, Allison JP, Jungbluth A, Wolchok JD (2011) CTLA-4 blockade increases antigen-specific CD8(+) $\mathrm{T}$ cells in prevaccinated patients with melanoma: three cases. Cancer Immunol Immunother 60(8):1137-1146

23. Liakou CI, Kamat A, Tang DN, Chen H, Sun J, Troncoso P, Logothetis C, Sharma P (2008) CTLA-4 blockade increases IFNgamma-producing CD4 + ICOShi cells to shift the ratio of effector to regulatory $\mathrm{T}$ cells in cancer patients. Proc Natl Acad Sci USA 105(39):14987-14992

24. Pedicord VA, Montalvo W, Leiner IM, Allison JP (2010) Single dose of anti-CTLA-4 enhances CD8 + T-cell memory formation, function, and maintenance. Proc Natl Acad Sci USA 108(1):266-271

25. Greten TF, Manns MP, Korangy F (2011) Myeloid derived suppressor cells in human diseases. Int Immunopharmacol 11(7):802-807

26. Filipazzi P, Huber V, Rivoltini L (2011) Phenotype, function and clinical implications of myeloid-derived suppressor cells in cancer patients. Cancer Immunol Immunother 61(2):255-263

27. Nagaraj S, Gabrilovich DI (2010) Myeloid-derived suppressor cells in human cancer. Cancer J 16(4):348-353

28. Dumitru CA, Moses K, Trellakis S, Lang S, Brandau S (2012) Neutrophils and granulocytic myeloid-derived suppressor cells: immunophenotyping, cell biology and clinical relevance in human oncology. Cancer Immunol Immunother 61(8):1155-1167

29. Gabrilovich DI, Ostrand-Rosenberg S, Bronte V (2012) Coordinated regulation of myeloid cells by tumours. Nat Rev Immunol 12(4):253-268

30. Poschke I, Mougiakakos D, Hansson J, Masucci GV, Kiessling $\mathrm{R}$ (2010) Immature immunosuppressive CD14 + HLA-DR-/low cells in melanoma patients are Stat $3 \mathrm{hi}$ and overexpress CD80, CD83, and DC-sign. Cancer Res 70(11):4335-4345

31. Filipazzi P, Valenti R, Huber V, Pilla L, Canese P, Iero M, Castelli C, Mariani L, Parmiani G, Rivoltini L (2007) Identification of a new subset of myeloid suppressor cells in peripheral blood of melanoma patients with modulation by a granulocyte-macrophage colony-stimulation factor-based antitumor vaccine. J Clin Oncol 25(18):2546-2553

32. Gros A, Turcotte S, Ahmadzadeh M, Wunderlich JR, Dudley ME, Rosenberg SA (2012) Myeloid cells obtained from the blood but not from the tumor can suppress $\mathrm{T}$ cell proliferation in patients with melanoma. Clin Cancer Res 18(19):5212-5223

33. Kusmartsev S, Su Z, Heiser A, Dannull J, Eruslanov E, Kubler H, Yancey D, Dahm P, Vieweg J (2008) Reversal of myeloid cellmediated immunosuppression in patients with metastatic renal cell carcinoma. Clin Cancer Res 14(24):8270-8278

34. Mirza N, Fishman M, Fricke I, Dunn M, Neuger AM, Frost TJ, Lush RM, Antonia S, Gabrilovich DI (2006) All-trans-retinoic acid improves differentiation of myeloid cells and immune response in cancer patients. Cancer Res 66(18):9299-9307

35. van Cruijsen $\mathrm{H}$, van der Veldt AA, Vroling L, Oosterhoff $\mathrm{D}$, Broxterman HJ, Scheper RJ, Giaccone G, Haanen JB, van den Eertwegh AJ, Boven E, Hoekman K, de Gruijl TD (2008) Sunitinib-induced myeloid lineage redistribution in renal cell cancer patients: $\mathrm{CD} 1 \mathrm{c}+$ dendritic cell frequency predicts progressionfree survival. Clin Cancer Res 14(18):5884-5892

36. Nagaraj S, Nelson A, Youn JI, Cheng P, Quiceno D, Gabrilovich DI (2012) Antigen-specific CD4 $+\mathrm{T}$ cells regulate function of myeloid-derived suppressor cells in cancer via retrograde MHC class II signaling. Cancer Res 72(4):928-938

37. Baniyash M (2004) TCR zeta-chain downregulation: curtailing an excessive inflammatory immune response. Nat Rev Immunol 4(9):675-687

38. Walker LS, Sansom DM (2011) The emerging role of CTLA4 as a cell-extrinsic regulator of $\mathrm{T}$ cell responses. Nat Rev Immunol 11(12):852-863

39. Michels T, Shurin GV, Naiditch H, Sevko A, Umansky V, Shurin MR (2012) Paclitaxel promotes differentiation of myeloidderived suppressor cells into dendritic cells in vitro in a TLR4independent manner. J Immunotoxicol 9(3):292-300

40. Parmiani G, Castelli C, Pilla L, Santinami M, Colombo MP, Rivoltini L (2007) Opposite immune functions of GM-CSF administered as vaccine adjuvant in cancer patients. Ann Oncol 18(2):226-232 
41. Naiditch H, Shurin MR, Shurin GV (2011) Targeting myeloid regulatory cells in cancer by chemotherapeutic agents. Immunol Res 50(2-3):276-285

42. Mantovani A (2010) The growing diversity and spectrum of action of myeloid-derived suppressor cells. Eur J Immunol 40(12):3317-3320

43. Del Vecchio M, Mortarini R, Tragni G, Di Guardo L, Bersani I, Di Tolla G, Agustoni F, Colonna V, Weber JS, Anichini A (2011) T-cell activation and maturation at tumor site associated with objective response to ipilimumab in metastatic melanoma. J Clin Oncol 29(32):783-788

44. Mandruzzato S, Solito S, Falisi E, Francescato S, Chiarion-Sileni V, Mocellin S, Zanon A, Rossi CR, Nitti D, Bronte V, Zanovello P (2009) IL4Ralpha + myeloid-derived suppressor cell expansion in cancer patients. J Immunol 182(10):6562-6568

45. Ohki S, Shibata M, Gonda K, Machida T, Shimura T, Nakamura I, Ohtake T, Koyama Y, Suzuki S, Ohto H, Takenoshita S (2012) Circulating myeloid-derived suppressor cells are increased and correlate to immune suppression, inflammation and hypoproteinemia in patients with cancer. Oncol Rep 28(2):453-458

46. Tarhini A (2012) Neoadjuvant ipilimumab in locally/regionally advanced melanoma: clinical outcome and immune monitoring. $\mathbf{J}$ Clin Oncol 30:Abstract 8553

47. Tarhini AA, Butterfield LH, Shuai Y, Gooding WE, Kalinski P, Kirkwood JM (2012) Differing patterns of circulating regulatory $\mathrm{T}$ cells and myeloid-derived suppressor cells in metastatic melanoma patients receiving anti-CTLA4 antibody and interferonalpha or TLR-9 agonist and GM-CSF with peptide vaccination. J Immunother 35(9):702-710

48. Wang XB, Giscombe R, Yan Z, Heiden T, Xu D, Lefvert AK (2002) Expression of CTLA-4 by human monocytes. Scand J Immunol 55(1):53-60

49. Comin-Anduix B, Sazegar H, Chodon T, Matsunaga D, Jalil J, von Euw E, Escuin-Ordinas H, Balderas R, Chmielowski B,
Gomez-Navarro J, Koya RC, Ribas A (2010) Modulation of cell signaling networks after CTLA4 blockade in patients with metastatic melanoma. PLoS ONE 5(9):e12711

50. Diaz-Montero CM, Salem ML, Nishimura MI, Garrett-Mayer E, Cole DJ, Montero AJ (2008) Increased circulating myeloidderived suppressor cells correlate with clinical cancer stage, metastatic tumor burden, and doxorubicin-cyclophosphamide chemotherapy. Cancer Immunol Immunother 58(1):49-59

51. Ostrand-Rosenberg S, Sinha P (2009) Myeloid-derived suppressor cells: linking inflammation and cancer. J Immunol 182(8):4499-4506

52. Ji RR, Chasalow SD, Wang L, Hamid O, Schmidt H, Cogswell J, Alaparthy S, Berman D, Jure-Kunkel M, Siemers NO, Jackson JR, Shahabi V (2011) An immune-active tumor microenvironment favors clinical response to ipilimumab. Cancer Immunol Immunother 61(7):1019-1031

53. Walter S, Weinschenk T, Stenzl A, Zdrojowy R, Pluzanska A, Szczylik C, Staehler M, Brugger W, Dietrich PY, Mendrzyk R, Hilf N, Schoor O, Fritsche J, Mahr A, Maurer D, Vass V, Trautwein C, Lewandrowski P, Flohr C, Pohla H, Stanczak JJ, Bronte V, Mandruzzato S, Biedermann T, Pawelec G, Derhovanessian E, Yamagishi H, Miki T, Hongo F, Takaha N, Hirakawa K, Tanaka H, Stevanovic S, Frisch J, Mayer-Mokler A, Kirner A, Rammensee HG, Reinhardt C, Singh-Jasuja H (2012) Multipeptide immune response to cancer vaccine IMA901 after single-dose cyclophosphamide associates with longer patient survival. Nat Med 18(8):1254-1261

54. Gabitass RF, Annels NE, Stocken DD, Pandha HA, Middleton GW (2011) Elevated myeloid-derived suppressor cells in pancreatic, esophageal and gastric cancer are an independent prognostic factor and are associated with significant elevation of the Th2 cytokine interleukin-13. Cancer Immunol Immunother 60(10):1419-1430 